\title{
Article \\ Over-Optimistic Projected Future Wheat Yield Potential in the North China Plain: The Role of Future Climate Extremes
}

\author{
Rui Yang ${ }^{1,+}$, Panhong Dai ${ }^{2,3,+}$, Bin Wang ${ }^{4,+}{ }^{\mathbb{D}}$, Tao Jin ${ }^{1}$, Ke Liu ${ }^{5} \mathbb{D}$, Shah Fahad ${ }^{6,7}$, Matthew Tom Harrison ${ }^{5}(\mathbb{D}$, \\ Jianguo Man ${ }^{8}$, Jiandong Shang ${ }^{9}$, Holger Meinke ${ }^{10} \mathbb{D}$, Deli Liu ${ }^{4} \mathbb{D}$, Xiaoyan Wang ${ }^{1, *}$, Yunbo Zhang ${ }^{1}$, \\ Meixue Zhou ${ }^{5}$ (D), Yingbing Tian ${ }^{1}$ and Haoliang Yan ${ }^{2, *}$
}

check for updates

Citation: Yang, R.; Dai, P.; Wang, B.; Jin, T.; Liu, K.; Fahad, S.; Harrison, M.T.; Man, J.; Shang, J.; Meinke, H.; et al. Over-Optimistic Projected Future Wheat Yield Potential in the North China Plain: The Role of Future Climate Extremes. Agronomy 2022, 12, 145. https://doi.org/10.3390/ agronomy12010145

Academic Editor: Sanja Cavar Zeljkovic

Received: 16 November 2021 Accepted: 23 December 2021 Published: 7 January 2022

Publisher's Note: MDPI stays neutral with regard to jurisdictional claims in published maps and institutional affiliations.

Copyright: (C) 2022 by the authors. Licensee MDPI, Basel, Switzerland. This article is an open access article distributed under the terms and conditions of the Creative Commons Attribution (CC BY) license (https:// creativecommons.org/licenses/by/ $4.0 /)$.
1 Engineering Research Center of Ecology and Agricultural Use of Wetland, College of Agriculture, Yangtze University, Jingzhou 434025, China; 201571413@yangtzeu.edu.cn (R.Y.); jintao@yangtzeu.edu.cn (T.J.); yzhang@yangtzeu.edu.cn (Y.Z.); tyb918@yangtzeu.edu.cn (Y.T.)

2 State Key Laboratory of Cotton Biology, Institute of Cotton Research of the Chinese Academy of Agricultural Sciences, Anyang 455000, China; 201673031@yangtzeu.edu.cn

3 School of Computer Science \& Information Engineering, Anyang Institute of Technology, Anyang 455000, China

4 New South Wales Department of Primary Industries, Wagga Wagga Agriculture Institute, Wagga Wagga 2650, Australia; bin.a.wang@dpi.nsw.gov.au (B.W.); de.li.liu@dpi.nsw.gov.au (D.L.)

5 Tasmanian Institute of Agriculture, University of Tasmania, 16-20 Mooreville Rd, Burnie 7320, Australia; ke.liu@utas.edu.au (K.L.); matthew.harrison@utas.edu.au (M.T.H.); meixue.zhou@utas.edu.au (M.Z.)

6 Hainan Key Laboratory for Sustainable Utilization of Tropical Bioresource, College of Tropical Crops, Hainan University, Haikou 570228, China; shah.fahad@uoh.edu.pk

7 Department of Agronomy, The University of Haripur, Haripur 22620, Pakistan

8 MARA Key Laboratory of Crop Ecophysiology and Farming System in the Middle Reaches of the Yangtze River, College of Plant Science and Technology, Huazhong Agricultural University, Wuhan 430070, China; jgman@mail.hzau.edu.cn

9 National Supercomputing Center in Zhengzhou, Zhengzhou University, Zhengzhou 450001, China; sjd@zzu.edu.cn

10 University of Tasmania, Hobart 7001, Australia; Holger.Meinke@utas.edu.au

* Correspondence: author: wamail_wang@163.com (X.W.); yanhl1989@163.com (H.Y.)

+ These authors contributed equally to this work.

\begin{abstract}
Global warming and altered precipitation patterns pose a serious threat to crop production in the North China Plain (NCP). Quantifying the frequency of adverse climate events (e.g., frost, heat and drought) under future climates and assessing how those climatic extreme events would affect yield are important to effectively inform and make science-based adaptation options for agriculture in a changing climate. In this study, we evaluated the effects of heat and frost stress during sensitive phenological stages at four representative sites in the NCP using the APSIM-wheat model. climate data included historical and future climates, the latter being informed by projections from 22 Global Climate Models (GCMs) in the Coupled Model Inter-comparison Project phase 6 (CMIP6) for the period 2031-2060 (2050s). Our results show that current projections of future wheat yield potential in the North China Plain may be overestimated; after more accurately accounting for the effects of frost and heat stress in the model, yield projections for 2031-60 decreased from 31\% to 9\%. Clustering of common drought-stress seasonal patterns into key groups revealed that moderate drought stress environments are likely to be alleviated in the future, although the frequency of severe drought-stress environments would remain similar $(25 \%)$ to that occurring under the current climate. We highlight the importance of mechanistically accounting for temperature stress on crop physiology, enabling more robust projections of crop yields under future the burgeoning climate crisis.
\end{abstract}

Keywords: APSIM-wheat model; climate change; wheat yield; frost and heat; drought stress 


\section{Introduction}

Global warming and altered rainfall patterns induced by rising greenhouse gas emission are predicted to cause more widespread and extreme weather events [1], thereby threatening agricultural production and global food security [2]. A recent global study projected that a twofold increase in the wheat-growing area will be threatened by extremely high temperatures during critical developmental stages in a typical year by 2050 [3]. It is thus necessary to quantify the impact of extreme climate events on crop yields, to assess the risk to food security and to develop targeted adaptive strategies to alleviate climate change.

China is the world's largest consumer and producer of wheat. Given that it is one of the primary wheat cropping regions in China, wheat productivity in the North China Plain (NCP) has been declining due to increased extreme weather events (e.g., drought stress and temperature stress) driven by climate change, especially in the southern part [4]. These extreme weather events cause large wheat yield variability in the NCP [5]. With climate change, more cropping regions like NCP will face a greater risk of abiotic stress due to higher frequencies and greater magnitudes of extreme temperature and rainfall events [6] Therefore, there is a need to develop and implement adaptation strategies that alleviate the adverse effects of these events.

In the NCP, temperature and drought stress may occur at critical crop development stages. Understanding temporal and spatial variability in these stress-risk, wheat-cropping zones would benefit the model-assisted design of climate change adaptation strategies [7-9]. Modelling tools have been used to characterise both the water-deficit and the waterlogging stress patterns experienced by a crop at a regional or national level in many cropping zones [10,11]. More importantly, this approach has proven useful for breeding improved abiotic stress tolerance in crops adapting to climate change [12-14].

The interactions of climate change and management options can be analysed with process-based crop simulation models $[15,16]$. Future climate projections after downscaling from different general circulation models (GCMs) can serve as inputs for process-based models $[17,18]$. Numerous crop modelling studies have attempted to evaluate potential climate change impacts on wheat production in the NCP [19-21], but few studies have evaluated the frequency of adverse climate conditions (e.g., frost, heat and drought) in future climates and how those extreme climate events would affect wheat yield. To fill this knowledge gap, we aim to (a) evaluate the impact of future temperature stress on wheat yield across wheat cropping regions in Shandong province in the NCP, and (b) examine how drought-stress frequencies and seasonal typologies would influence yield under future climate change scenarios.

\section{Materials and Methods}

\subsection{Field Experimental and Phenotyping}

Field experiments were conducted at Yanzhou $\left(35^{\circ} 34^{\prime} \mathrm{N}, 116^{\circ} 51^{\prime} \mathrm{E}, 53.0 \mathrm{~m}\right.$ altitude) from 2015 to 2018 in Shandong province, China (Table 1). The soil in the upper $20 \mathrm{~cm}$ at the experimental site was calcareous alluvial with the following properties: $\mathrm{pH}$ 6.7, $20.7 \mathrm{~g} \mathrm{~kg}^{-1}$ organic matter, $635.8 \mathrm{mg} \mathrm{kg}^{-1}$ alkali-hydrolysable $\mathrm{N}, 29.7 \mathrm{mg} \mathrm{kg}^{-1}$ available $\mathrm{P}$, and $128.9 \mathrm{mg} \mathrm{kg}^{-1}$ available K. Soil property data were collected each year and averaged across the three years.

Table 1. Detailed information for field experiments conducted at Yanzhou in Shandong province.

\begin{tabular}{|c|c|c|c|c|c|c|}
\hline Year & $\begin{array}{l}\text { Sowing Date } \\
\text { (d-m-y) }\end{array}$ & $\begin{array}{l}\text { Flowering Date } \\
\text { (d-m-y) }\end{array}$ & $\begin{array}{c}\text { Maturity Date } \\
\text { (d-m-y) }\end{array}$ & $\begin{array}{c}\text { Fertilisation } \\
\left(\mathrm{kg} \mathrm{N} \mathrm{ha}^{-1}\right)\end{array}$ & 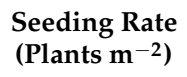 & $\begin{array}{l}\text { Irrigation } \\
\text { (mm) }\end{array}$ \\
\hline 2015-2016 & 13 October 2015 & 14 April 2016 & 14 May 2016 & 105 (basal) + $105($ ZS31) & 180 & $60($ ZS31) + $61($ ZS60) \\
\hline 2016-2017 & 12 October 2016 & 13 April 2017 & 13 May 2017 & 105 (basal) + 105 (ZS31) & 180 & $44(\mathrm{ZS} 31)+38(\mathrm{ZS} 60)$ \\
\hline 2017-2018 & 23 October 2017 & 24 April 2018 & 20 May 2018 & 105 (basal) + $105(\mathrm{ZS} 31)$ & 270 & $45(\mathrm{ZS} 31)+45(\mathrm{ZS} 60)$ \\
\hline
\end{tabular}

A winter wheat cultivar, Jimai22 with medium vernalisation and photoperiod response, was used in the field experiment. This high-yielding cultivar has mid-to-late maturity and 
is widely planted in Shandong province. The plants were planted in $2 \times 6 \mathrm{~m}$ plots with a row spacing of $25 \mathrm{~cm}$. Experiments were arranged in a randomized, completed block design with three replications. The plants were sown with a seeding rate of 180 seeds $\mathrm{m}^{-2}$ in autumn and were harvested the next summer. The sowing date was 13 October 2015, 12 October 2016 and 23 October 2017, respectively. Plants were fertilised with $105 \mathrm{~kg} \mathrm{~N} \mathrm{ka} \mathrm{ha}{ }^{-1}$, $65 \mathrm{~kg} \mathrm{P} \mathrm{ha}^{-1}$ and $93 \mathrm{~kg} \mathrm{~K} \mathrm{ha}^{-1}$ as basal fertiliser for the three experimental seasons. During the growth periods, all the plots were top-dressed with $105 \mathrm{~kg} \mathrm{~N} \mathrm{ha}^{-1}$ at the jointing stage (ZS31). Irrigation was applied at ZS31 with $60 \mathrm{~mm}$ and at anthesis with $44 \mathrm{~mm}$ to alleviate water stress. Weed control was performed from emergence to harvesting by hand hoeing. No incidence of pest or disease infection occurred in either experiment.

Crop phenology was measured every two weeks following the Zadoks Stage. The dates of sowing, anthesis and maturity were recorded for each year. At anthesis and maturity (ZS90), 30 plants were taken to measure the total aboveground biomass. The biomass weight of leaves and stems were determined after oven-drying at $70{ }^{\circ} \mathrm{C}$ to a constant weight. At maturity (ZS90), plants from $4 \mathrm{~m}^{2}$ areas were harvested for the determination of grain yield (at $13 \%$ grain moisture) and yield components.

\subsection{Model Simulation}

\subsubsection{APSIM-Wheat}

In this study, simulations were conducted using APSIM-Wheatv7.9 [22]. The performance of APSIM-wheat has been widely tested and verified for cropping system simulations across China. In an APSIM-Wheat module, phenological development is described in terms of thermal time accumulation using 11 crop stages and 10 phases (time between stages). The duration of each stage is determined by the accumulation of thermal time, calculated as the sum of the average daily temperature above a base temperature, which is defined as the temperature under which no significant crop development is expected. The daily thermal time values are likely to be further influenced by photoperiod, vernalisation and other environmental factors such as drought and heat stress. Potential daily biomass production is calculated using radiation use efficiency (RUE), which is defined as the amount of dry matter produced per unit of photosynthetically active radiation that is intercepted by the crop canopy. Grain yield, which is a function of crop growth and crop development, is impacted by RUE, transpiration efficiency and leaf nitrogen concentrations; these parameters are accounted for in the model. In APSIM, grain yield is determined by the kernel set number and the average kernel weight at maturity, as these are the main grain yield determinants in most crops.

\subsubsection{Model Parameterisation and Validation}

Parameterisation (Table 2) was performed by minimising the sum of squared errors for measured and simulated phenology, biomass and yield following the approach outlined by Harrison et al. [23]. Field data measured at Yanzhou in 2015 were used for parameterisation while data obtained in 2016 and 2017 were used for validation. We applied the evaluation criteria outlined by Harrison et al. [23], where the ideal root-mean square error (RMSE) and mean bias $(\mathrm{MB})$ values are represented by $0.0 ; \mathrm{MB}<1$ and $\mathrm{MB}>1$ represent model underestimation and overestimation of observed data, respectively. Relative root-mean square error (RRMSE) values of $<5 \%=$ excellent, $5-10 \%=$ very good, $10-30 \%=$ good and $>30 \%=$ poor. The ideal variance ratio (VR) is $1 ; \mathrm{VR}>1$ indicates greater variation in the actual data compared with the simulated data. Calibrated genetic parameters showed in Table 3.

\subsubsection{Factorial Simulations}

Factorial simulations were conducted for 1981-2010 (hereafter referred to as baseline) at four locations representing the major wheat producing areas across Shandong province (Figure 1). Parameterised genotype was used to conduct long-term simulations. Wheat was sown at 180 plants $\mathrm{m}^{-2}$, at a depth of $3 \mathrm{~cm}$ with a row spacing of $25 \mathrm{~cm}$. Nitrogen 
(N) was applied as urea with a fertiliser rule, with a first dose of $105 \mathrm{~kg} \mathrm{~N} \mathrm{ha}^{-1}$ applied at sowing and a second dose of $105 \mathrm{~kg} \mathrm{~N} \mathrm{ha}^{-1}$ applied when the first node of the stem was visible (ZS 31). To elicit the effects of sowing time on phenology, yield and other agronomic indicators, sowing windows were simulated using five-day increments from 1 October to 21 October each year. To ensure crops were successfully germinated across all sowing dates, $15 \mathrm{~mm}$ of irrigation was applied for each simulation. The initial soil conditions were reset each year to exclude any 'carry-over' effects from previous seasons. Soil parameters for each of the ten $20 \mathrm{~cm}$ thick soil layers were set at reference values according to International Soil Reference and Information Centre [24].

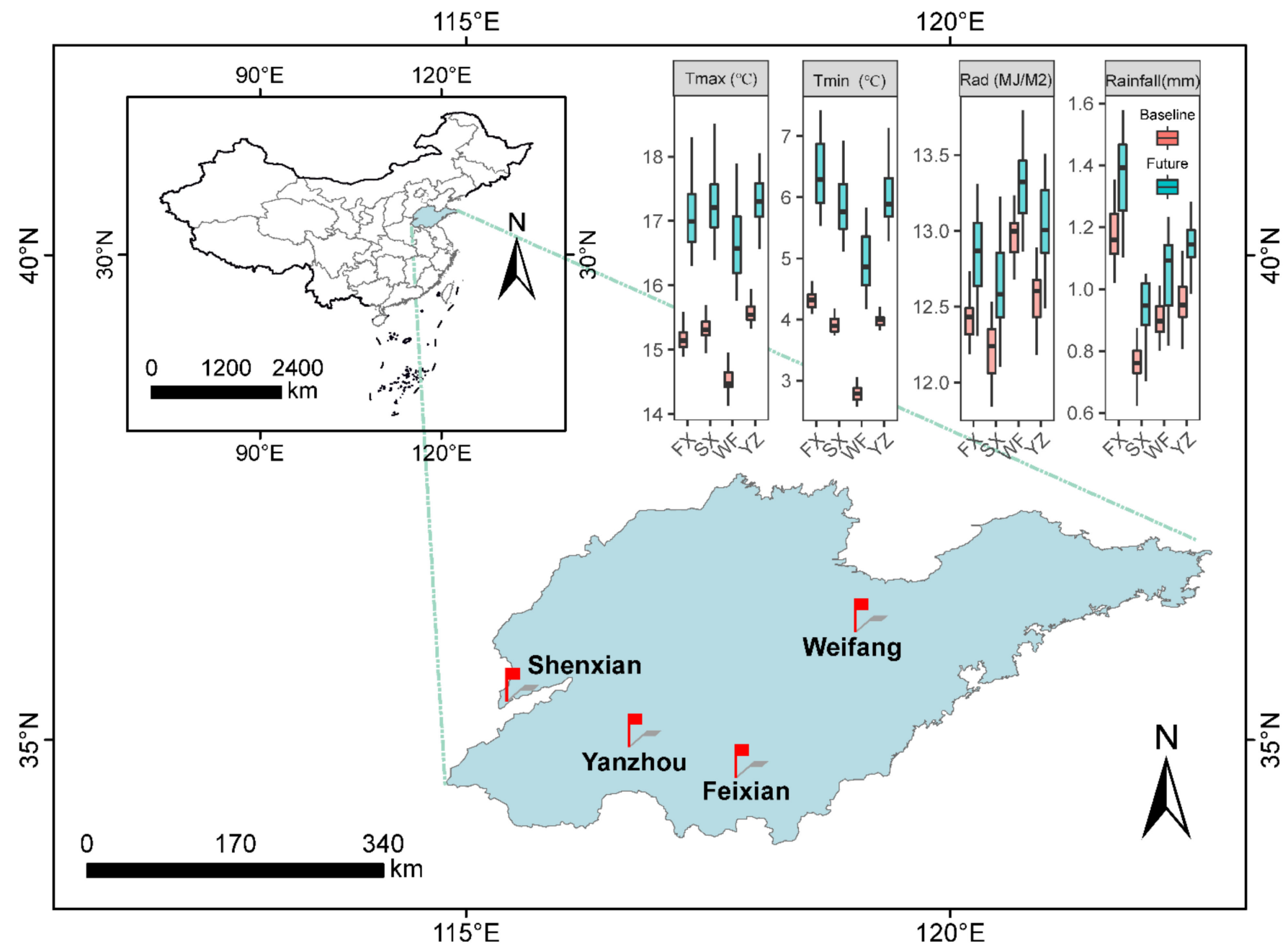

Figure 1. Four sites (Shenxian: SX; Yanzhou: YZ; Feixian: FX; Weifang: WF) located in Shandong province used for simulations in this study.

Table 2. Verification statistics of APSIM-Wheat simulations. Data shown are mean observed and simulated values in 2016-2017 and 2017-2018.

\begin{tabular}{|c|c|c|c|c|c|}
\hline Variables & RMSE & $\mathbf{R}^{2}$ & MB & RRMSE & VR \\
\hline Flowering days (d) & 2.1 & 0.91 & -0.1 & $4 \%$ & 1.06 \\
\hline Maturity days $(\mathrm{d})$ & 3.2 & 0.97 & 0.2 & $3 \%$ & 0.95 \\
\hline Maturity biomass $\left(\mathrm{kg} \mathrm{ha}^{-1}\right)$ & 281 & 0.95 & -1.3 & $4.2 \%$ & 1.01 \\
\hline Grain yield $\left(\mathrm{kg} \mathrm{ha}^{-1}\right)$ & 321 & 0.95 & -3.6 & $4.5 \%$ & 1.03 \\
\hline
\end{tabular}


Table 3. Calibrated genetic parameters of a winter wheat, Jimai22.

\begin{tabular}{|c|c|c|c|}
\hline Parameters & Definition & Unit & Value \\
\hline tt_end_of juvenile & Thermal time from sowing to end of juvenile & ${ }^{\circ} \mathrm{C}$ day $^{-1}$ & 450 \\
\hline tt_start_grain_fill & Thermal time from start grain filling to maturity & ${ }^{\circ} \mathrm{C}$ day $^{-1}$ & 655 \\
\hline grains_per_gram_stem & Kernel number per stem weight at the beginning of grain filling & $\mathrm{g}$ & 30 \\
\hline potential_grain_filling_rate & Potential daily grain filling rate & g grain $^{-1}$ day $^{-1}$ & 0.003 \\
\hline max_grain_size & Maximum grain size & $\mathrm{g}$ & 0.045 \\
\hline vern_sens & Vernalisation sensitivity & & 3.0 \\
\hline Photo_sens & Photoperiod sensitivity & & 2.5 \\
\hline rue from $\mathrm{ZS} 30$ to $\mathrm{ZS} 90$ & Radiation use efficiency & $\mathrm{g} \mathrm{MJ}^{-1}$ & 1.49 \\
\hline
\end{tabular}

\subsubsection{Simulating the Effect of Frost and Heat Damage on Yield}

To estimate the effect of frost and heat damage during sensitive growth stages on yield, we used the damage function developed by Bell et al., (2015) [25] for wheat. The temperature ranges were categorised into mild, medium and severe stress with a corresponding impact on yield during different development stages, as shown in Table S1. Following the default version of APSIM-Wheat [26] and Bell et al., (2015) [25], yield on day i was modelled as:

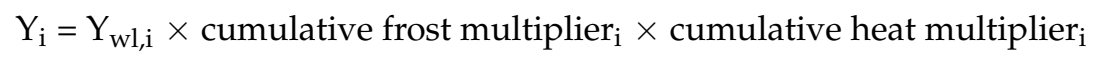

where

$\mathrm{Y}_{\mathrm{wl}, \mathrm{i}}=$ water-limited yield on day $\mathrm{i}$

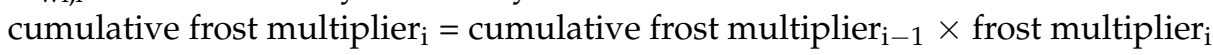

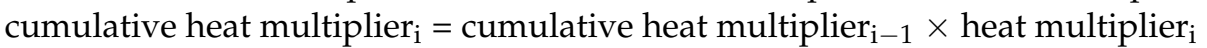
Daily frost or heat multipliers were read from Flohr et al., (2017) [27] in the model according to Zadoks stage. More details are described in our previous study [15].

\subsubsection{Climate Data}

Historical daily climate data of the four representative agro-meteorological stations were obtained from China's Meteorological Administration (CMA). Future climate (2031-2060; hereafter refer to 2050s) projections were based on 22 global climate models (GCM, Table 4) from CMIP6 (https:/ / esgf-node.1lnl.gov/projects/cmip6/; (accessed on 2 October 2021)). These climate projections were driven by a new set of integrated assessment models (IAMs) based on the Shared Socioeconomic Pathways (SSPs) and the Representative Concentration Pathways (RCPs) [28]. In this study, we used future climate projections for one integrated scenario (combining SSP5 with RCP8.5, defined by SSP585). SSP585 envisions fossil-fueled development pathway with rapid technological progress and development of human capital [28], and RCP8.5 is a high radiative forcing pathway ( $8.5 \mathrm{~W} \mathrm{~m}^{-2}$ in 2100).

During the baseline period, $\mathrm{CO}_{2}$ concentration was set to $380 \mathrm{ppm}$ for all simulation years in the model. Under the SSP585 scenario, $\mathrm{CO}_{2}$ concentrations will continuously rise to 936 ppm by 2100 [29], which was fitted with a calendar year based on Wang et al., (2019):

$$
\left[\mathrm{CO}_{2}\right] \text { year }=1034.3+\frac{267.78-1.618 * y}{4.0143+\frac{53.342}{y^{5.2822}}}+21.746 *\left(\frac{y-2010}{100}\right)^{3}+100.65 *\left(\frac{y-1911}{100}\right)^{3}
$$

where $y$ was the calendar year from 1900 to $2100(y=1900,1901, \ldots, 2100)$.

To produce future climate data, observed climate data were required to correct biases of monthly GCM outputs as part of the statistical downscaling procedure [30]. Here, we used a statistical downscaling method developed by the Department of Primary Industries of New South Wales, Australia [17]. This method used bias-corrected monthly GCM climate data (temperature, rainfall and radiation data) to generate realistic time series of daily climate data for each study site based on a modified weather generator. 
Table 4. List of 22 global climate models (GCMs) used in this study.

\begin{tabular}{ccccc}
\hline No. & GCM & Abbreviation & Institution & Country \\
\hline 1 & ACCESS-CM2 & ACC1 & CSIRO-ARCCSS & Australia \\
2 & ACCESS- ESM1-5 & ACC2 & CSIRO-ARCCSS & Australia \\
3 & BCC-CSM2-MR & BCC & BCC & China \\
4 & CanESM5 & CAN1 & CCCMA & Canada \\
5 & CanESM5-CanOE & CAN2 & CCCMA & Canada \\
6 & CNRM-CM6-1 & CNR1 & CNRM & France \\
7 & CNRM-CM6-1-HR & CNR1 & CNRM & France \\
8 & CNRM-ESM2-1 & CNR2 & CNRM & France \\
9 & EC-Earth3-Veg & ECE1 & EC-EARTH & Europe \\
10 & EC-Earth3 & ECE2 & EC-EARTH & Europe \\
11 & FGOALS-g3 & FGO & FGOALS & China \\
12 & GFDL-ESM4 & GFD & NOAA-GFDL & America \\
13 & GISS-E2-1-G & GIS & NASA-GISS & America \\
14 & INM-CM4-8 & INM1 & INM & Russia \\
15 & INM-CM5-0 & INM2 & INM & Russia \\
16 & IPSL-CM6A-LR & IPS & IPSL & France \\
17 & MPI-ESM1-2-HR & MPI & MPI-M & Germany \\
18 & MPI-ESM1-2-LR & MPI2 & MPI-M & Germany \\
19 & MIROC6 & MIR1 & MIROC & Japan \\
20 & MIROC-ES2L & MIR2 & MIROC & Japan \\
21 & MRI-ESM2-0 & MRI & MRI & Japan \\
22 & UKESM1-0-LL & U0L & UKESM & U. K \\
\hline
\end{tabular}

\subsubsection{Last Frost Day, First Heat Day and Target Flowering Windows}

For each site, the last frost day (LFD) was defined as the last day of the year with a minimum air temperature below $0{ }^{\circ} \mathrm{C}$ [31], and the first heat day (FHD) was calculated as the first day with a maximum air temperature greater than $35^{\circ} \mathrm{C}$ [32]. The frost and heat risks of each site were calculated in both cases using the 70th percentile, such that LFD refers to the date having a $30 \%$ chance of $0{ }^{\circ} \mathrm{C}$, while the FHD corresponds to the date with $30 \%$ chance of experiencing a $35{ }^{\circ} \mathrm{C}$ day. LFD and FHD dates were computed for each site using climate data from 1981 to 2010 and 2031 to 2060. The 'target flowering window' for each site and genotype was then calculated using the LFD and FHD specified above, such that flowering of a given genotype at a specific site occurred between LFD and FHD [33].

\subsubsection{Long-Term Seasonal Water Stress Typologies and Frequencies}

The time series of the ratio of crop water supply to demand for each site $\times$ soil $\times$ year simulation were centered on flowering and averaged $100{ }^{\circ} \mathrm{C}$ every day from emergence to maturity, following Harrison et al. [9] and Liu et al. [7]. Cluster analysis was applied to all simulated time series using the k-means clustering algorithm ( $\mathrm{R}$ Development Core Team, 2011) to identify mean drought-stress seasonal patterns. Four drought-stress seasonal patterns accounted for more than $75 \%$ of the variance across all baseline or 2050 simulations. Further details of this method are described by $[10,34]$.

\section{Results}

\subsection{Validation of APSIM-Wheat Model}

The simulated anthesis and maturity were consistent with the observed dates based on model calibration and validation results (Figure 2A). The $R^{2}$ between simulated and observed phenology dates was greater than 0.91 and RMSE was 2-3 d (Table 2). The simulated yields also closely followed the observations, with $R^{2}=0.95$ and RRMSE $=5 \%$ (Table 2). The results indicated that the APSIM-Wheat could effectively simulate wheat growth and development under rain-fed conditions in the NCP. The calibrated parameters are shown in Table 3. 

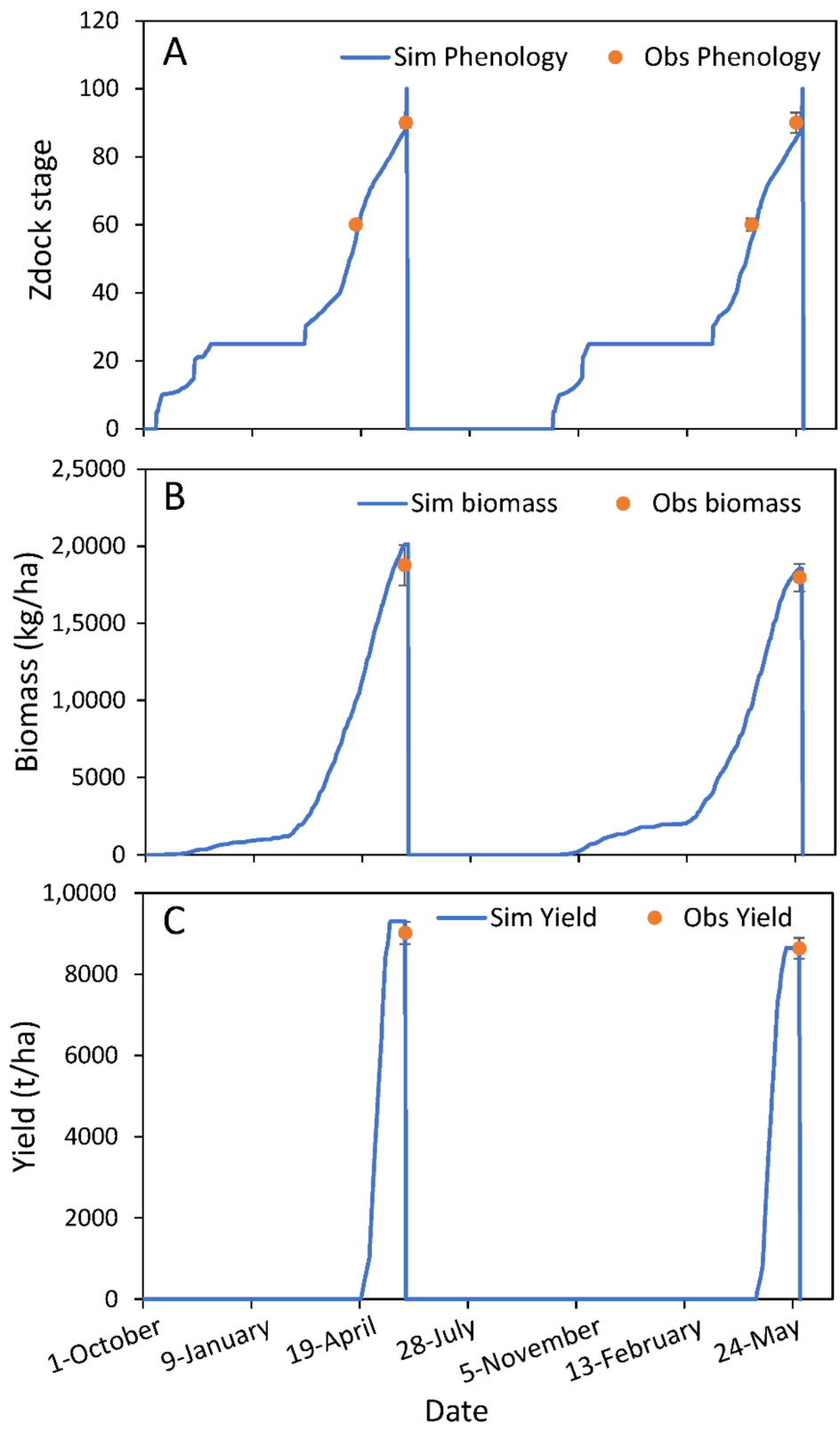

Figure 2. Simulated and observed phenology (A), maturity biomass (B) and grain yield (C) for "Jimai22" in 2016-2017 and 2017-2018 at Yanzhou.

\subsection{Wheat Productivity under Future Climates}

Without considering the effects of extreme climate stress (e.g., heat and frost stress), wheat yields are projected to show an increasing trend (Figure 3) across sites in the near future (2050s). The average long-term yield increases in this study were $31 \%$ across sowing dates and sites, with the largest increase at Yanzhou (38\%) and the smallest increase at Shenxian (27\%). Simulated yield decreased with sowing dates under the baseline (Figure S1), but the fluctuation of yield under future climates is minor; thus, the relative change of water-limited potential yield increased with sowing dates (Figure 3).

After including the effect of frost and heat stress in the model, averaged water-limited yield decreased by $17 \%$ across sites and sowing dates, and the yield reduction was mainly caused by heat stress (i.e., heat-limited yield). Simulated yield loss caused by heat stress was much higher than that caused by frost due to climate warming across sites. The yield increase in water-limited potential yield in the 2050s decreased from $31 \%$ to $9 \%$ (heat and 
frost limited yield). This difference was especially pronounced at Weifang and Shenxian, while Feixian and Yanzhou are affected by heat and frost stress to a lesser extent.

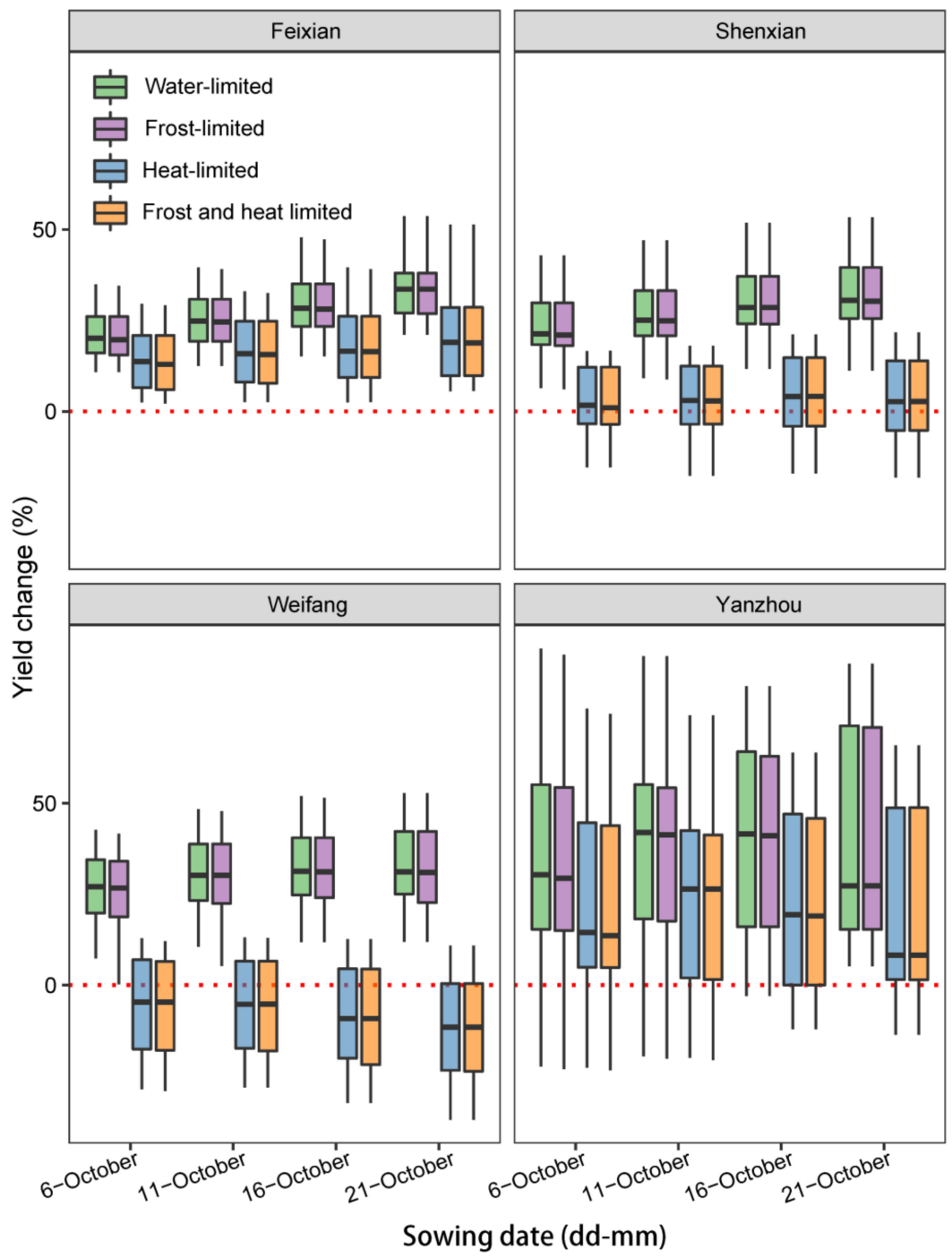

Figure 3. Yield changes in the period of 2030-2061 (referred as 2050s) under SSP585 compared with the water-limited potential yield of baseline period (1981-2010). Water-limited potential yield (i.e., not limited by frost and heat). Frost-limited yield (i.e., water-limited potential yields are reduced due to frost stress during the sensitive period). Heat-limited yield (i.e., water-limited potential yields are reduced due to heat stress during the sensitive period). Frost and heat limited yield (i.e., water-limited potential yields are reduced due to both heat and frost stress during the sensitive period).

\subsection{Cumulative Probability of Heat and Frost Stress during the Flowering Window}

Low-risk windows were calculated to avoid yield damage caused by frost and heat. Then, sowing dates would be determined in order to meet the sensitive period during flowering that coincided with this low-risk period (shaded zone in Figure 4). For each location, low-risk sowing window was defined as the range of sowing dates allowing flowering to occur within the low risk of heat and frost stress.

There were large differences in the timing and duration of low-stress windows across sites. In the current time, flowering windows generally coincided with the low-risk period and the cumulative probability of heat and frost stress during the flowering periods were lower than $30 \%$ across sites. The longest flowering window was at Shenxian (from 30 April to 27 May, Figure 4C) and the shortest at Weifang (from 20 April to 17 May, Figure 4E). 


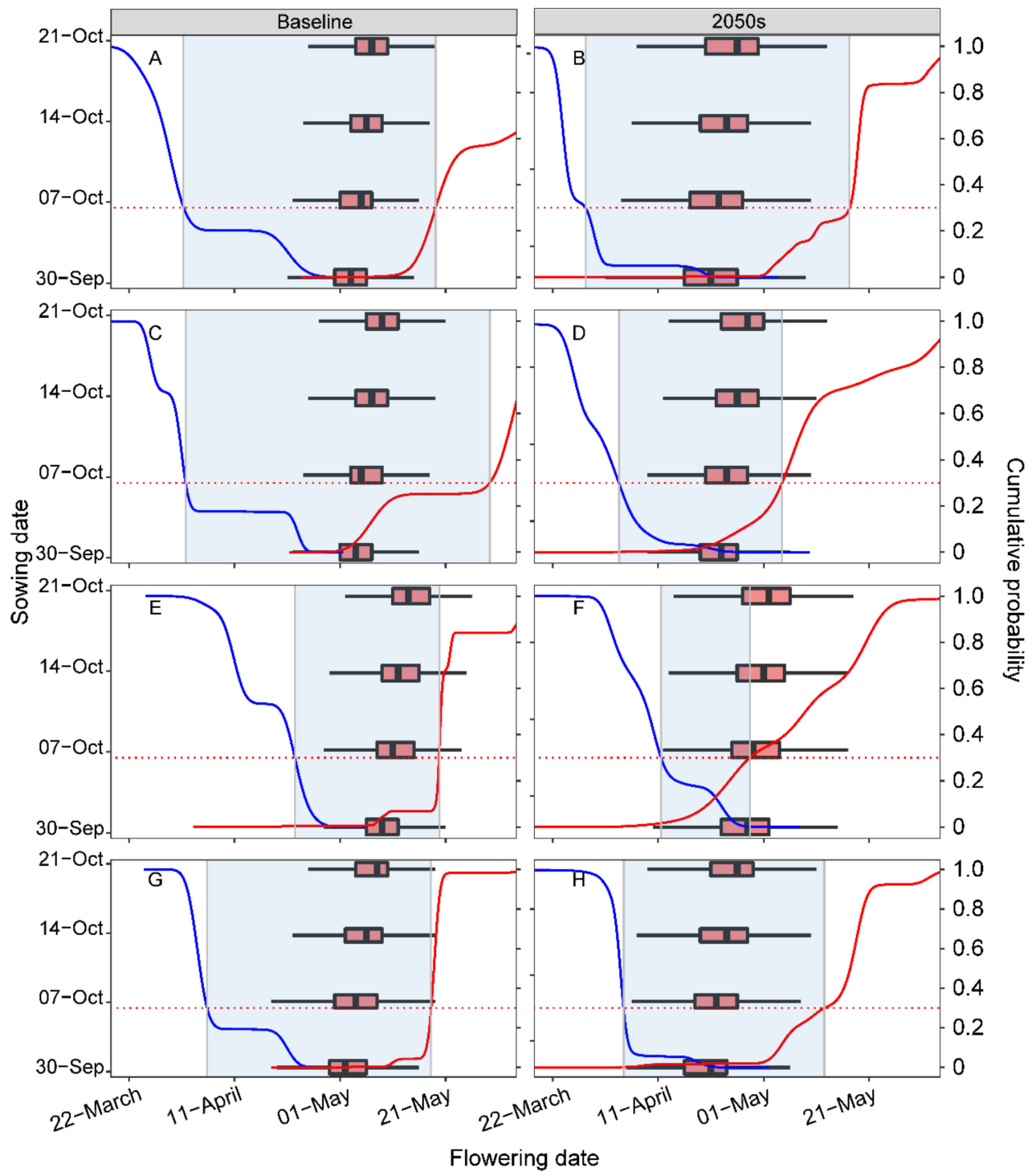

Figure 4. Impact of sowing date on the timing of flowering compared to the occurrence of extremetemperature events under the periods of 1981-2010 (baseline) and 2031-2060 (2050s) across sites $((\mathbf{A}, \mathbf{B})$ Feixian; (C,D) Shenxian; (E,F) Weifang; (G,H) Yanzhou). The boxplot shows the variation in flowering date ( $x$-axis) for different sowing dates (left $y$-axis) over 30 years. Probabilities of last frost days (left blue solid line), and first heat days (right red solid line) are calculated as the percentiles of last frost and first heat days for baseline and 2050s. The low-risk period for frost and heat and preferred flowering window is highlighted in grey. The upper horizontal dashed red line indicates the $30 \%$ risk of first heat and frost day.

In the future climate scenarios, low-risk flowering windows shifted forward (4 days and 14 days earlier for first day of frost and last days of heat stress, respectively) across sites due to increased temperatures. For these frost-free sites, the largest shift occurred at Weifang (Figure 4F), where both the maximum and minimum temperatures increased by $2.2{ }^{\circ} \mathrm{C}$ and the cumulative probability of heat stress during flowering windows was greater than 30\% across sowing dates. Feixian (from 28-March to 17-May) and Yanzhou (from 4-April to 1-May) still coincided with the low-risk period under future climates (Figure $4 \mathrm{~B}, \mathrm{H}$ ). 


\subsection{Seasonal Drought Stress under Future Climates}

Our cluster analysis based on all simulations across four sites revealed three dominant drought-stress response (Figure 5A,B) patterns. Under historical climate conditions, around $46 \%$ of simulations experienced low drought stress (DT2), with a median yield across all simulations of $6528 \mathrm{~kg} \mathrm{ha}^{-1}$ (Figure 5C). The remaining 54\% were classed into two categories according to the timing of onset and intensity of drought stress. Severe stress with late recovery drought (DT3, 25\% of cases) was most detrimental for yield (median yield approx. $2701 \mathrm{~kg} \mathrm{ha}^{-1}$ ), followed by early moderate stress (DT2, median yield approx. $5706 \mathrm{~kg} \mathrm{ha}^{-1}$ ) (Figure 5C).
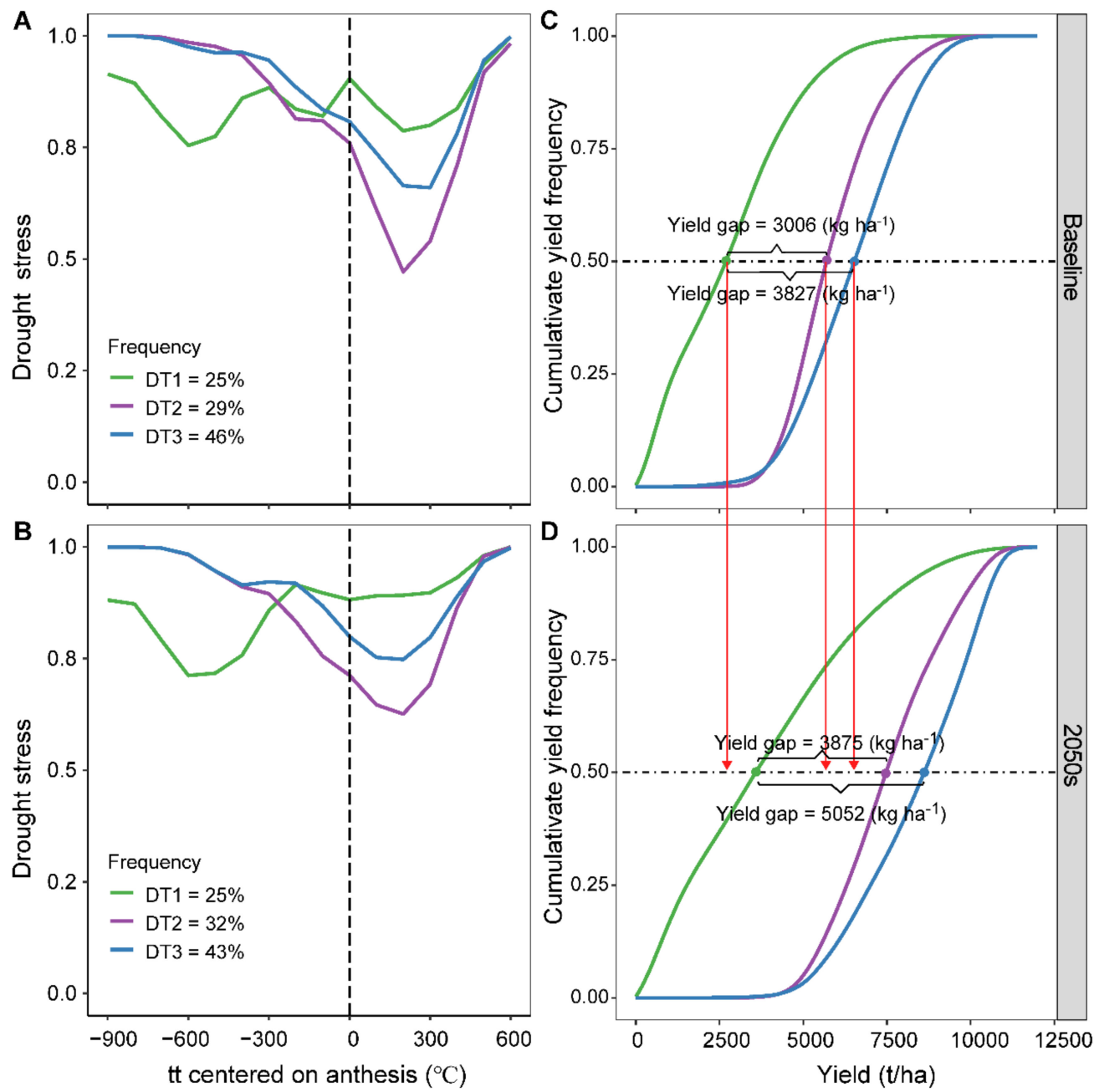

Figure 5. Crop drought-stress trajectories $(1=$ no stress and $0=$ full stress $)$ and trend over crop development stage expressed as thermal time (tt) before or after anthesis under historical (A) and future climates (B). (See individual site in Supplementary Figures S2-S5). Three types of droughtstress patterns (DT1: early-onset severe stress; DT2: severe stress with late recovery; DT3: moderate stress with late recovery) identified by k-means clustering. Cumulative simulated yield frequencies across all sowing dates in each drought patterns are shown for current ((C), 1981-2010) and future ((D), 2031-2060) climates. Points on curves indicate median yield for each drought pattern in each climate scenario. Vertical arrows are included for comparison across climate scenarios. Curly brackets indicate yield gap between different drought types.

Clustering of all simulations under future climates indicated that the magnitude of drought stress was projected to be alleviated. In spite of this, it was projected that the frequency of DT3, which has the most detrimental effects on yield, would remain the same $(25 \%)$ in the near future. More importantly, such drought type was expected to 
cause a larger yield gap in the 2050s. The yield gap between DT1 and DT3 increased from $3827 \mathrm{~kg} \mathrm{ha}^{-1}$ in baseline periods to $5052 \mathrm{~kg} \mathrm{ha}^{-1}$, and from $3006 \mathrm{~kg} \mathrm{ha}^{-1}$ to $3875 \mathrm{~kg} \mathrm{ha}^{-1}$ between DT1 and DT2. The typology of three seasonal drought patterns remained similar to those occurring historically.

\section{Discussion}

Numerous crop modelling studies have attempted to evaluate potential climate change impacts on wheat production in the North China Plain, but few studies have evaluated the frequency of adverse climate conditions (e.g., frost, heat and drought) under future climates and how these extreme events would affect wheat yield. In this study, we evaluated the adverse effects of heat and frost stress on wheat yields by integrating yield reduction multipliers caused by heat and frost events during temperature sensitive stages into an APSIM-wheat model. Our results showed that current projections of future wheat yield potential in the NCP were overestimated due to an ignorance about the role of climate extremes. We used a cluster analysis approach to characterise drought-stress patterns of winter wheat crops and thus determined how such patterns may differ in future. Clustering all drought-stress patterns into key groups revealed important differences between typologies and frequencies of the major stress patterns occurring in the study area.

In many parts of the world, climate change will result in decreased rainfall, at least in the crop growing season (e.g., Australian Wheatbelt). In the current study, however, future climates predicted by 22 GCMs in CMIP6 showed that most study sites will face a larger increase in temperature and rainfall, coupled with a decrease in solar radiation under the SSP585 scenario (Figure 1). This positive insight for future climate change contradicts most other studies, which herald negative implications of climate change. However, such beneficial effects are not observed in some studies in the NCP. For example, a detailed analysis of China based on global gridded crop model outputs has also reported a future 10-30\% reduction in the mean yield in the NCP, except for on its northern border [35]. Another simulation driven by 30 GCMs from the CMIP5 reported that the wheat mean yield would decrease by $2.4-12.3 \%$ under RCP 8.5 [36]. Using decomposed and reassembled climate change scenarios, Liu et al., found that climate change is projected to reduce wheat yield by $17 \%$ under RCP8.5 [5]. These negative effects of climate change on yields are exaggerated because these studies neither account for increased atmospheric $\mathrm{CO}_{2}$ concentrations, which can offset negative effects of climate change on yield, nor management practices (e.g., fertilisation or irrigation input).

If $\mathrm{CO}_{2}$ fertilisation effects is accounted for in the model, wheat yields are projected to show an increasing trend (Figure 4) across sites for the near future (2050s), where the average long-term yield increased by $31 \%$. Such positive effects are in agreement with many previous studies [19,37-39]. These results were somewhat too optimistic because temperature stress is not accounted for in the model, which can cause a severe yield reduction during the sensitive stages. In the current study, after including the effect of frost and heat stress, the magnitude of the increased yield in the 2050s became small (9\%, Figure 2). Our results suggest the importance of including temperature stress effect on wheat yield in the climate change impact assessment since climate warming is an indisputable fact [40].

Globally, rising temperatures and heat stress are the main drivers of projected negative climate change impacts on crop yields [41,42]. In this study, we found that the yield reduction was mainly caused by heat stress and that the simulated yield loss caused by heat stress was much higher across sites than the simulated yield loss caused by frost stress (Figure 2). A short period of $100{ }^{\circ} \mathrm{C}$ before anthesis and up to 7 days after anthesis (while grains are still forming) can significantly reduce grain yield by increasing the proportion of aborting grains $[43,44]$. Our study showed that several sites (e.g., Shenxian and Weifang) were projected to face a high risk of heat stress during the flowering periods under future climates (Figure 3). In the two regions, early sowing of short-season varieties is preferable for flowering in minimal risk periods. In the other environments (e.g., Feixian and Yanzhou), 
which have lower late season (terminal) water, there would be a lower risk of heat stress during the flowering periods and thus higher yields, because lower abiotic stress exposure near the end of the growing season would be conducive to greater biomass and grain production. Climate warming is leading to early springs and delayed autumns in colder environments, allowing plants to grow for a longer period of time during each growth period, which encourages farmers to delay the winter wheat sowing date in the NCP. Late sowing might become quite a common way of coping with climate change under future climates, but at a high risk of heat stress during the flowering periods. Thus, assessing wheat potential to mitigate the adverse effects of future rising temperatures and heat stress in the NCP still should be a focus for future studies.

In addition to heat and frost stress, drought stress is another factor limiting yield potential in the NCP. These regions are projected to suffer a high frequency of DT1, which is most detrimental for yield, in the near future, and the extreme drought stress might cause more severe yield penalties (Figure 5). To breed genotypes with improved drought tolerance, it is necessary to characterise the typology and frequency of drought patterns experienced by crops both under historical and future climates [45-47]. Our results showed that drought-stress patterns expected under future conditions will be similar to those occurring under present conditions (Figure 5). This result has many important implications for breeding drought-tolerant genotypes. If the major drought-stress patterns expected under future conditions were unlike those experienced currently, then crop breeding for future conditions would be difficult, as seasonal patterns in future climates might not occur under field conditions at frequencies high enough to influence the direction of germplasm development in breeding trials. In such cases, crop adaptation to specific drought-stress seasonal patterns would need to be performed under controlled-stress environments, as suggested by Bänziger et al. [48]. However, as the typologies of the key drought-stress seasonal patterns occurring under present conditions are likely to be similar to those expected in future climates, selection of elite wheat germplasm for superior yield under present conditions using field trials should be an appropriate method for developing germplasm suitable for the near future. Despite the higher temperatures and increased winter precipitation predicted in the NCP for the 2050s, the impact of drought stress on simulated wheat yield is predicted to be smaller in most cases (32-43\%; See DT2 and DT3 in Figure 5B,D). However, the probability of heat stress around flowering that might result in considerable yield losses is predicted to increase significantly (Figure 4). Breeding strategies for the future climate might need to focus on wheat varieties tolerant to high temperatures more than to drought.

In this study, we used a multiple model ensemble method to address the uncertainties from climate models. To assess the impacts of extreme temperature on wheat yield, we integrated yield reduction multipliers caused by heat and frost events during temperature sensitive stages into an APSIM-wheat model based on relevant research reports. Due to limited data for model evaluation, our modelling results might over- or underestimate the magnitude of yield losses resulting from heat and frost stress, as Chen et al., (2020) [49] did before. Nonetheless, capturing heat and frost losses to grain yield in some way could provide guidance for developing adaptation strategies to reduce climate risks [25,50]. Further improvement of the definitions and physiological basis of this approach would enhance the accuracy of these predictions. In this study, we only used three years of field experimental data to validate the APSIM Wheat module. This might cause some uncertainties in simulated phenology due to unexplained abiotic or biotic factors affecting the phenology of crops in the field. More verification data may be useful to improve the validity of APSIM Wheat in simulating the phenology of Jimai22. We used only one crop model in our study, which might omit the uncertainty of yield projections caused by crop model structure [51]. Moreover, in the APSIM-wheat model, the increased photosynthesis due to elevated atmospheric was reported mainly from controlled, semi-controlled and open-field experiments [52]. Therefore, the crop model might overestimate the positive 
effects of elevated atmospheric. As such, we acknowledge that the results presented here depend on the scenario and crop model chosen.

\section{Conclusions}

In this study we evaluated the adverse effects of heat and frost stress on wheat yields by integrating yield reduction multipliers caused by heat and frost events into an APSIMwheat model. Our results showed that after including the effect of frost and heat stress in the model, the yield increases in wheat potential yield in the 2050s decreased from $31 \%$ to $9 \%$. In addition, clustering all drought-stress seasonal patterns into key groups revealed that the magnitude of drought stress was projected to be alleviated in the future but that the frequency of DT1 (most detrimental stress for yield) would remain the same (around 25\%) in the near future. These results provide important information for assessing the impacts of climate extremes on wheat yield and highlight the fact that adopting heat-tolerant cultivars should be a priority to cope with climate change in the NCP.

Supplementary Materials: The following are available online at https://www.mdpi.com/article/10 .3390/agronomy12010145/s1, Figure S1: Boxplot showed yield in the period of 1981-2010 (referred as baseline) and 2030-2061 (referred as 2050s) under SSP585, Figure S2: Crop drought-stress trajectories and trend over crop development stage before or after anthesis under historical and future climates in Feixian, Figure S3: Crop drought-stress trajectories and trend over crop development stage before or after anthesis under historical and future climates in Shenxian, Figure S4: Crop drought-stress trajectories and trend over crop development stage before or after anthesis under historical and future climates in Weifang, Figure S5: Crop drought-stress trajectories and trend over crop development stage before or after anthesis under historical and future climates in Yanzhou.

Author Contributions: Conceptualization, K.L., P.D. and H.Y.; methodology, R.Y., K.L., P.D., T.J. and H.Y.; software, R.Y., K.L., J.S. and H.Y.; validation, R.Y., P.D. and H.Y.; formal analysis, R.Y., P.D. and H.Y.; investigation, P.D., H.Y. and R.Y.; resources, J.M., K.L., P.D. and H.Y.; data curation, R.Y., J.M., K.L., P.D. and H.Y.; writing-original draft preparation, R.Y. and P.D. writing—review and editing, B.W., M.T.H., H.M., S.F., D.L., K.L. and M.Z.; visualization, P.D. and H.Y.; supervision, X.W., Y.Z. and Y.T.; project administration, X.W., Y.T. and J.M.; funding acquisition, X.W. and J.M. All authors have read and agreed to the published version of the manuscript.

Funding: This research was funded by [National Science Foundation of China] grant number [31871578 and 32172108], [National Key Research \& Development Program of China during the 13th Five-year Period] grant number [2016YFD0300107] and [Engineering Research Center of Ecology and Agricultural Use of Wetland] grant number [KFT202102].

Institutional Review Board Statement: Not applicable.

Informed Consent Statement: Not applicable.

Data Availability Statement: Data is contained within the article or Supplementary Materials.

Acknowledgments: We thank Jiandong Shang of the National Supercomputing Center in Zhengzhou, Zhengzhou University, for providing the Computing resources.

Conflicts of Interest: The authors declare no conflict of interest.

\section{References}

1. Cook, B.I.; Smerdon, J.E.; Seager, R.; Coats, S. Global warming and 21st century drying. Clim. Dyn. 2014, 43, 2607-2627. [CrossRef]

2. Wheeler, T.; von Braun, J. Climate Change Impacts on Global Food Security. Science 2013, 341, 508-513. [CrossRef]

3. Gourdji, S.M.; Sibley, A.M.; Lobell, D.B. Global crop exposure to critical high temperatures in the reproductive period: Historical trends and future projections. Environ. Res. Lett. 2013, 8, 024041. [CrossRef]

4. Xiao, D.; Tao, F. Contributions of cultivars, management and climate change to winter wheat yield in the North China Plain in the past three decades. Eur. J. Agron. 2014, 52, 112-122. [CrossRef]

5. Liu, W.; Ye, T.; Shi, P. Decreasing wheat yield stability on the North China Plain: Relative contributions from climate change in mean and variability. Int. J. Climatol. 2021, 41, E2820-E2833. [CrossRef]

6. You, Q.; Cai, Z.; Wu, F.; Jiang, Z.; Pepin, N.; Shen, S.S.P. Temperature dataset of CMIP6 models over China: Evaluation, trend and uncertainty. Clim. Dyn. 2021, 57, 17-35. [CrossRef] 
7. Liu, K.; Harrison, M.T.; Archontoulis, S.V.; Huth, N.; Yang, R.; Liu, D.L.; Yan, H.; Meinke, H.; Huber, I.; Feng, P.; et al. Climate change shifts forward flowering and reduces crop waterlogging stress. Environ. Res. Lett. 2021, 16, 094017. [CrossRef]

8. Wang, B.; Feng, P.; Chen, C.; Liu, D.L.; Waters, C.; Yu, Q. Designing wheat ideotypes to cope with future changing climate in South-Eastern Australia. Agric. Syst. 2019, 170, 9-18. [CrossRef]

9. Harrison, M.T.; Tardieu, F.; Dong, Z.; Messina, C.D.; Hammer, G.L. Characterizing drought stress and trait influence on maize yield under current and future conditions. Glob. Change Biol. 2014, 20, 867-878. [CrossRef]

10. Chenu, K.; Deihimfard, R.; Chapman, S.C. Large-scale characterization of drought pattern: A continent-wide modelling approach applied to the Australian wheatbelt-Spatial and temporal trends. New Phytol. 2013, 198, 801-820. [CrossRef]

11. Harrison, M.T.; Cullen, B.R.; Mayberry, D.E.; Cowie, A.L.; Bilotto, F.; Badgery, W.B.; Liu, K.; Davison, T.; Christie, K.M.; Muleke, A.; et al. Carbon myopia: The urgent need for integrated social, economic and environmental action in the livestock sector. Glob. Change Biol. 2021, 27, 5726-5761. [CrossRef]

12. Hammer, G.L.; McLean, G.; Chapman, S.; Zheng, B.; Doherty, A.; Harrison, M.T.; van Oosterom, E.; Jordan, D. Crop design for specific adaptation in variable dryland production environments. Crop Pasture Sci. 2014, 65, 614-626. [CrossRef]

13. Hammer, G.L.; McLean, G.; van Oosterom, E.; Chapman, S.; Zheng, B.; Wu, A.; Doherty, A.; Jordan, D. Designing crops for adaptation to the drought and high-temperature risks anticipated in future climates. Crop Sci. 2020, 60, 605-621. [CrossRef]

14. Yan, H.; Harrison, M.T.; Liu, K.; Wang, B.; Feng, P.; Fahad, S.; Meinke, H.; Yang, R.; Liu, D.L.; Archontoulis, S.; et al. Crop traits enabling yield gains under more frequent extreme climatic events. Sci. Total Environ. 2022, 808, 152170. [CrossRef]

15. Liu, K.; Harrison, M.T.; Hunt, J.; Angessa, T.T.; Meinke, H.; Li, C.; Tian, X.; Zhou, M. Identifying optimal sowing and flowering periods for barley in Australia: A modelling approach. Agric. For. Meteorol. 2020, 282-283, 107871. [CrossRef]

16. Liu, K.; Harrison, M.T.; Shabala, S.; Meinke, H.; Ahmed, I.; Zhang, Y.; Tian, X.; Zhou, M. The State of the Art in Modeling Waterlogging Impacts on Plants: What Do We Know and What Do We Need to Know. Earth's Future 2020, 8, e2020EF001801. [CrossRef]

17. Liu, D.L.; Zuo, H. Statistical downscaling of daily climate variables for climate change impact assessment over New South Wales, Australia. Clim. Change 2012, 115, 629-666. [CrossRef]

18. Wang, B.; Feng, P.; Liu, D.L.; O’Leary, G.J.; Macadam, I.; Waters, C.; Asseng, S.; Cowie, A.; Jiang, T.; Xiao, D.; et al. Sources of uncertainty for wheat yield projections under future climate are site-specific. Nat. Food 2020, 1, 720-728. [CrossRef]

19. Xiao, D.; Liu, D.L.; Wang, B.; Feng, P.; Bai, H.; Tang, J. Climate change impact on yields and water use of wheat and maize in the North China Plain under future climate change scenarios. Agric. Water Manag. 2020, 238, 106238. [CrossRef]

20. Mo, X.; Liu, S.; Lin, Z.; Guo, R. Regional crop yield, water consumption and water use efficiency and their responses to climate change in the North China Plain. Agric. Ecosyst. Environ. 2009, 134, 67-78. [CrossRef]

21. Wang, J.; Wang, E.; Yang, X.; Zhang, F.; Yin, H. Increased yield potential of wheat-maize cropping system in the North China Plain by climate change adaptation. Clim. Change 2012, 113, 825-840. [CrossRef]

22. Holzworth, D.P.; Huth, N.I.; deVoil, P.G.; Zurcher, E.J.; Herrmann, N.I.; McLean, G.; Chenu, K.; van Oosterom, E.J.; Snow, V.; Murphy, C.; et al. APSIM-Evolution towards a new generation of agricultural systems simulation. Environ. Model. Softw. 2014, 62,327-350. [CrossRef]

23. Harrison, M.T.; Roggero, P.P.; Zavattaro, L. Simple, efficient and robust techniques for automatic multi-objective function parameterisation: Case studies of local and global optimisation using APSIM. Environ. Model. Softw. 2019, 117, 109-133. [CrossRef]

24. Batjes, N.H.; Ribeiro, E.; van Oostrum, A. Standardised soil profile data to support global mapping and modelling (WoSIS snapshot 2019). Earth Syst. Sci. Data 2020, 12, 299-320. [CrossRef]

25. Lilley, J.M.; Bell, L.W.; Kirkegaard, J.A. Optimising grain yield and grazing potential of crops across Australia's high-rainfall zone: A simulation analysis. 2. Canola. Crop Pasture Sci. 2015, 66, 349-364. [CrossRef]

26. Keating, B.A.; Carberry, P.S.; Hammer, G.L.; Probert, M.E.; Robertson, M.J.; Holzworth, D.; Huth, N.I.; Hargreaves, J.N.G.; Meinke, H.; Hochman, Z.; et al. An overview of APSIM, a model designed for farming systems simulation. Eur. J. Agron. 2003, 18, 267-288. [CrossRef]

27. Flohr, B.M.; Hunt, J.R.; Kirkegaard, J.A.; Evans, J.R. Water and temperature stress define the optimal flowering period for wheat in south-eastern Australia. Field Crops Res. 2017, 209, 108-119. [CrossRef]

28. O'Neill, B.C.; Tebaldi, C.; van Vuuren, D.P.; Eyring, V.; Friedlingstein, P.; Hurtt, G.; Knutti, R.; Kriegler, E.; Lamarque, J.F.; Lowe, J.; et al. The Scenario Model Intercomparison Project (ScenarioMIP) for CMIP6. Geosci. Model Dev. 2016, 9, $3461-3482$. [CrossRef]

29. Van Vuuren, D.P.; Edmonds, J.; Kainuma, M.; Riahi, K.; Thomson, A.; Hibbard, K.; Hurtt, G.C.; Kram, T.; Krey, V.; Lamarque, J.-F.; et al. The representative concentration pathways: An overview. Clim. Change 2011, 109, 5. [CrossRef]

30. Liu, D.L.; Zeleke, K.T.; Wang, B.; Macadam, I.; Scott, F.; Martin, R.J. Crop residue incorporation can mitigate negative climate change impacts on crop yield and improve water use efficiency in a semiarid environment. Eur. J. Agron. 2017, 85, 51-68. [CrossRef]

31. Boer, G.J. Climate change and the regulation of the surface moisture and energy budgets. Clim. Dyn. 1993, 8, 225-239. [CrossRef]

32. Stone, P.J.; Nicolas, M.E. Wheat Cultivars Vary Widely in Their Responses of Grain Yield and Quality to Short Periods of Post-Anthesis Heat Stress. Funct. Plant Biol. 1994, 21, 887-900. [CrossRef] 
33. Zheng, B.; Chenu, K.; Fernanda Dreccer, M.; Chapman, S.C. Breeding for the future: What are the potential impacts of future frost and heat events on sowing and flowering time requirements for Australian bread wheat (Triticum aestivium) varieties? Glob. Change Biol. 2012, 18, 2899-2914. [CrossRef]

34. Chenu, K.; Porter, J.R.; Martre, P.; Basso, B.; Chapman, S.C.; Ewert, F.; Bindi, M.; Asseng, S. Contribution of Crop Models to Adaptation in Wheat. Trends Plant Sci. 2017, 22, 472-490. [CrossRef]

35. Yin, Y.; Tang, Q.; Liu, X. A multi-model analysis of change in potential yield of major crops in China under climate change. Earth Syst. Dyn. 2015, 6, 45-59. [CrossRef]

36. Xuan, Y.; Xu, T.; Bao-De, C.; Zhan, T.; Si-Jian, Z. Impacts of Climate Change on Wheat Yield in China Simulated by CMIP5 Multi-Model Ensemble Projections. Sci. Agric. Sin. 2014, 47, 3009-3024. [CrossRef]

37. Guo, R.; Lin, Z.; Mo, X.; Yang, C. Responses of crop yield and water use efficiency to climate change in the North China Plain. Agric. Water Manag. 2010, 97, 1185-1194. [CrossRef]

38. Rashid, M.A.; Jabloun, M.; Andersen, M.N.; Zhang, X.; Olesen, J.E. Climate change is expected to increase yield and water use efficiency of wheat in the North China Plain. Agric. Water Manag. 2019, 222, 193-203. [CrossRef]

39. Zhang, Y.; Feng, L.P.; Wang, J.; Wang, E.L.; Xu, Y.L. Using APSIM to explore wheat yield response to climate change in the North China Plain: The predicted adaptation of wheat cultivar types to vernalization. J. Agric. Sci. 2013, 151, 836-848. [CrossRef]

40. Sognnaes, I.; Gambhir, A.; van de Ven, D.-J.; Nikas, A.; Anger-Kraavi, A.; Bui, H.; Campagnolo, L.; Delpiazzo, E.; Doukas, H.; Giarola, S.; et al. A multi-model analysis of long-term emissions and warming implications of current mitigation efforts. Nat. Clim. Chang. 2021, 11, 1055-1062. [CrossRef]

41. Asseng, S.; Ewert, F.; Rosenzweig, C.; Jones, J.W.; Hatfield, J.L.; Ruane, A.C.; Boote, K.J.; Thorburn, P.J.; Rötter, R.P.; Cammarano, D.; et al. Uncertainty in simulating wheat yields under climate change. Nat. Clim. Chang. 2013, 3, 827-832. [CrossRef]

42. Asseng, S.; Jamieson, P.D.; Kimball, B.; Pinter, P.; Sayre, K.; Bowden, J.W.; Howden, S.M. Simulated wheat growth affected by rising temperature, increased water deficit and elevated atmospheric $\mathrm{CO}_{2}$. Field Crops Res. 2004, 85, 85-102. [CrossRef]

43. Yan, H.; Wang, C.; Liu, K.; Tian, X. Detrimental effects of heat stress on grain weight and quality in rice (Oryza sativa L.) are aggravated by decreased relative humidity. Peer] 2021, 9, e11218. [CrossRef]

44. Liu, K.; Deng, J.; Lu, J.; Wang, X.; Lu, B.; Tian, X.; Zhang, Y. High Nitrogen Levels Alleviate Yield Loss of Super Hybrid Rice Caused by High Temperatures During the Flowering Stage. Front. Plant Sci. 2019, 10, 357. [CrossRef]

45. Harrison, M.T.; Christie, K.M.; Rawnsley, R.P.; Eckard, R.J. Modelling pasture management and livestock genotype interventions to improve whole-farm productivity and reduce greenhouse gas emissions intensities. Anim. Prod. Sci. 2014, 54, 2018-2028. [CrossRef]

46. Harrison, M.T.; Cullen, B.R.; Armstrong, D. Management options for dairy farms under climate change: Effects of intensification, adaptation and simplification on pastures, milk production and profitability. Agric. Syst. 2017, 155, 19-32. [CrossRef]

47. Harrison, M.T.; Evans, J.R.; Dove, H.; Moore, A.D. Recovery dynamics of rainfed winter wheat after livestock grazing 2. Light interception, radiation-use efficiency and dry-matter partitioning. Crop Pasture Sci. 2011, 62, 960-971. [CrossRef]

48. Bänziger, M.; Setimela, P.S.; Hodson, D.; Vivek, B. Breeding for improved abiotic stress tolerance in maize adapted to southern Africa. Agric. Water Manag. 2006, 80, 212-224. [CrossRef]

49. Chen, C.; Wang, B.; Feng, P.; Xing, H.; Fletcher, A.L.; Lawes, R.A. The shifting influence of future water and temperature stress on the optimal flowering period for wheat in Western Australia. Sci. Total Environ. 2020, 737, 139707. [CrossRef]

50. Bell, M.J.; Eckard, R.J.; Harrison, M.T.; Neal, J.S.; Cullen, B.R. Effect of warming on the productivity of perennial ryegrass and kikuyu pastures in south-eastern Australia. Crop Pasture Sci. 2013, 64, 61-70. [CrossRef]

51. Tao, F.; Rötter, R.P.; Palosuo, T.; Díaz-Ambrona, C.G.H.; Mínguez, M.I.; Semenov, M.A.; Kersebaum, K.C.; Nendel, C.; Cammarano, D.; Hoffmann, H.; et al. Designing future barley ideotypes using a crop model ensemble. Eur. J. Agron. 2017, 82, 144-162. [CrossRef]

52. Kimball, B.A.; Kobayashi, K.; Bindi, M. Responses of Agricultural Crops to Free-Air $\mathrm{CO}_{2}$ Enrichment. In Advances in Agronomy; Sparks, D.L., Ed.; Academic Press: Cambridge, MA, USA, 2002; Volume 77, pp. 293-368. 